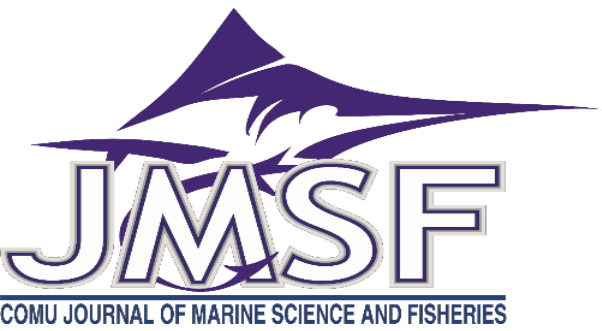

\title{
Determination of the Effect of Different Catching Methods Made with Gillnets on the Selectivity of Bogue (Boops boops Linneus, 1758)
}

\author{
Oğuzhan Ayaz*, Uğur Altınağaç \\ Çanakkale Onsekiz Mart Üniversitesi, Deniz Bilimleri ve Teknolojisi Fakültesi, Terzioğlu Yerleşkesi, 17100, Çanakkale/Türkiye \\ Correspondent: oguzhanayaz53@gmail.com
}


üzerinde yaygın olarak kullanılmasına sebep olmuştur (Altınağaç, Ayaz, Özekinci ve Öztekin, 2008). Uzatma ağlarının yaygın olarak kullanıldığ Türkiye'de de kıyı ve iç su balıkçılığı yapılan bölgelerimizde oldukça aktif olarak kullanılmaktadır. $\mathrm{Bu}$ bölgelerden biri de balık göçlerinin de yoğun olarak yaşandığı Kuzey Ege'de bulunan Çanakkale ili kıyılarıdır.

Kuzey Ege ve Çanakkale Boğazı kayalıklı ve çamur dip yapısına sahip, akıntının fazla, gemi trafiğinin yoğun olması gibi nedenlerden dolayı kıyı balıkçılığının endüstriyel balıkçılığa nazaran daha fazla yapıldığı ve uzatma ağlarının aktif kullanıldığ 1 bölgelerimizdendir. Özellikle sade uzatma ağları bu bölgede fanyalı ağlara nazaran oldukça yoğun kullanılmaktadır. Bu ağların seçiciliğinin yüksek olması ve hangi balığı, hangi boy aralığında yakaladığının bilinmesi balıkçılık yönetimi açısından son derece önemlidir (Millar, 1992; Millar ve Holts, 1997).

Uzatma ağı seçiciliğini etkileyen faktörler arasında; ağ göz genişliği, balığın vücut yapısı ve boyu, ağ ipinin kalınlığg, görünürlüğü ve esnekliği, donam faktörü, balık davranışları ve avcılık yöntemi olduğu belirtilmiştir (Clarke, 1960; Hamley, 1975). Seçiciliği etkileyen ana faktörün ağ göz genişliği olduğu bilindiğinden dolayı dünya üzerinde yapılan seçicilik çalışmaların birçoğunun bu faktör üzerine yapıldığı gözlenmiştir (Von Brandt, 1975). Dünyada ve Türkiye'de yapılan uzatma ağı seçiciliği çalışmaları incelendiğinde, avcılık yöntemini ele alan herhangi bir çalışmaya rastlanılamamıştır.

Çanakkale Boğazı'nda özellikle kış aylarında popülasyonu artan Kupes (Boops boops) balığının avlanmasında, galsama ağları dönek ve voli yöntemlerinin her ikisinde de kullanılmaktadır. Yunistan ve İtalya'ya kış aylarında ihracatı yapılması ve iç piyasada fiyatının makul olması nedeniyle Kupes balığının Çanakkale Boğazı ve ülkemiz için sosyoekonomik bir değeri vardır. Bu türün avcılığında 22 , 23, $25 \mathrm{~mm}$ göz genişliğinde ağlar kullanılmaktadır (Ayaz, Altınağaç, Öztekin ve Özekinci, 2009). Avcılık yöntemi farkının seçiciliği önemli derecede etkileyip etkilemediğinin bilinmesi balıkçılık yönetimi açısından önem arz etmektedir.

$\mathrm{Bu}$ çalışmada bölgede kupes avcılığında her iki yöntem (Voli ve Dönek) ile de kullanılan galsama ağlarının seçiciliklerini incelemek ve her iki yöntemin seçicilik üzerine etkisini belirlemek amaçlanmıştır.

\section{Materyal ve Yöntem}

Bu çalışma Mart 2020 - Nisan 2020 tarihleri arasında, Çanakkale ili sınırları içerisindeki Morto Koyu ve Seddülbahir Köyü kıyılarında, 4 farklı istasyonda, $2-15$ metre derinlikler arasinda toplamda 20 deneme yapılarak gerçekleştirilmiştir. Denemelerin gerçekleştirildiği saha Şekil 1.’de gösterilmiştir.

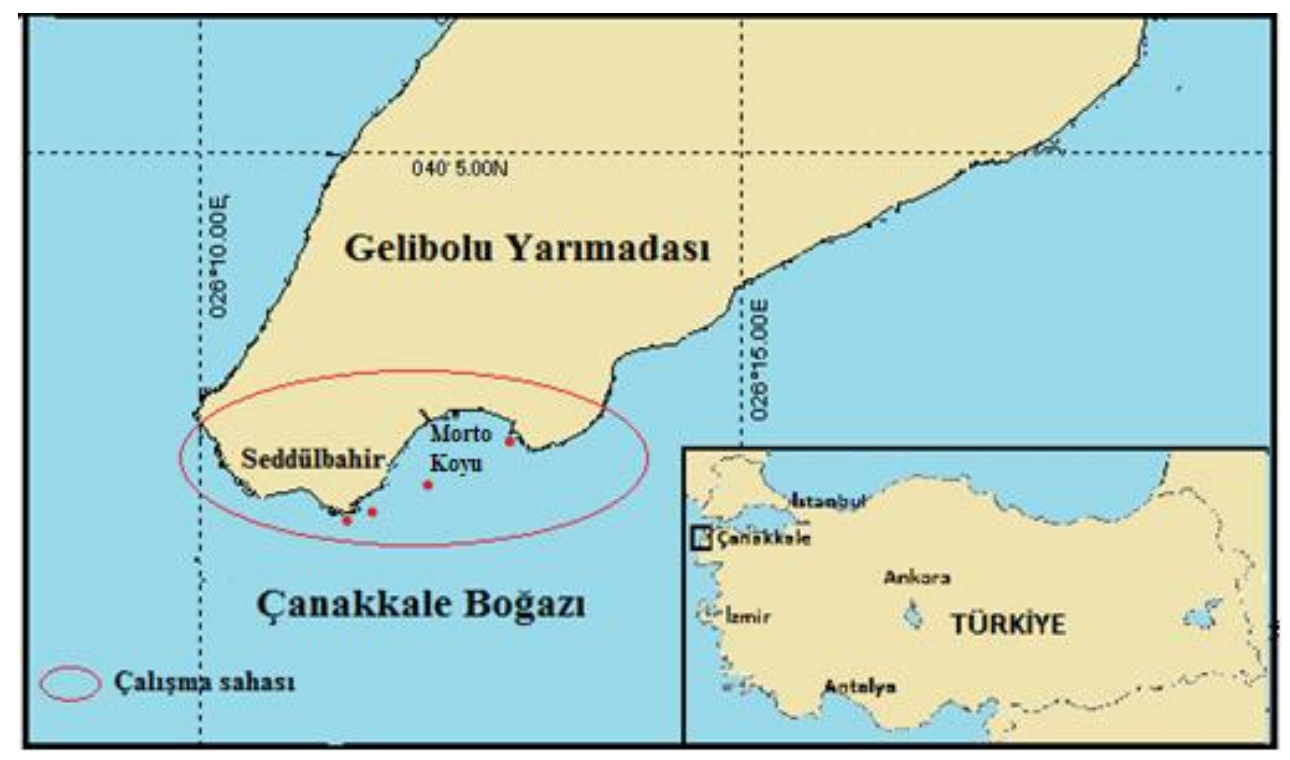

Şekil 1. Çalışma Sahası, Çanakkale Boğazı

Çalışmada multifilament PA, 210 d / 3 numara ip kalınlığına, $E=0,5$ donam faktörüne ve $20,22,23$ ve $25 \mathrm{~mm}$ göz genişliğine sahip galsama ağları kullanılmıştır. Her bir ağın göz yüksekliği 105 ve yaka uzunluğu $100 \mathrm{~m}$ olarak belirlenip yapılmıştır. Çalıșmada kullanılan galsama ağlarının sadece göz genişlikleri farklı olup diğer donam özellikleri birbiri ile aynı olacak şekilde yapılmıştır.

Deniz çalışmalarında, $7 \mathrm{~m}$ boyunda ve $55 \mathrm{HP}$ güce sahip Remzi Kaptan 17 isimli balıkçı teknesi kullanılmıştır. 
Çalışmada deneme ağları avcılık yönteminin seçiciliğe etkisini belirlemek amacıyla iki farklı yöntemde kullanılmıştır. Denemelerde 10 operasyon dönek ve 10 operasyon voli yöntemi uygulanmıştır. Operasyonlar yapılırken avcılık yöntemlerinin ardışık olarak yapılmasına özen gösterilmiştir.

Dönek yönteminde ağlar kıyıdan denize doğru dik olarak uzatılır. İki ucuna balığın hareket yönüne açık olacak şekilde kuzuluk yapılarak bırakılır. Yapılan kuzuluklar akıntının etkisi ile bozulmasın diye ağın kurşun yakasına 2 - 5 kg'lık belli aralıklar ile taş bağlanır. Gece hareket halinde olan balıklar kendi günlük göçü esnasında herhangi bir müdahale olmadan ağlara yakalanır (Şekil 2). Voli yönteminde ise balığın bulunduğu ya da olabileceği tahmin edilen bir bölgenin etrafı ağ ile çevrilerek, 1şık, ses ya da labut kullanılarak balığın ağa doğru korkutularak sürülmesi şeklinde operasyon yapılmaktadır (Gabriel, Lange, Dahm ve Wendt, 2005) (Şekil 3). Bu nedenle dönek yönteminde balığın ağa çarpma hızı voli yöntemine nazaran daha yavaștır.

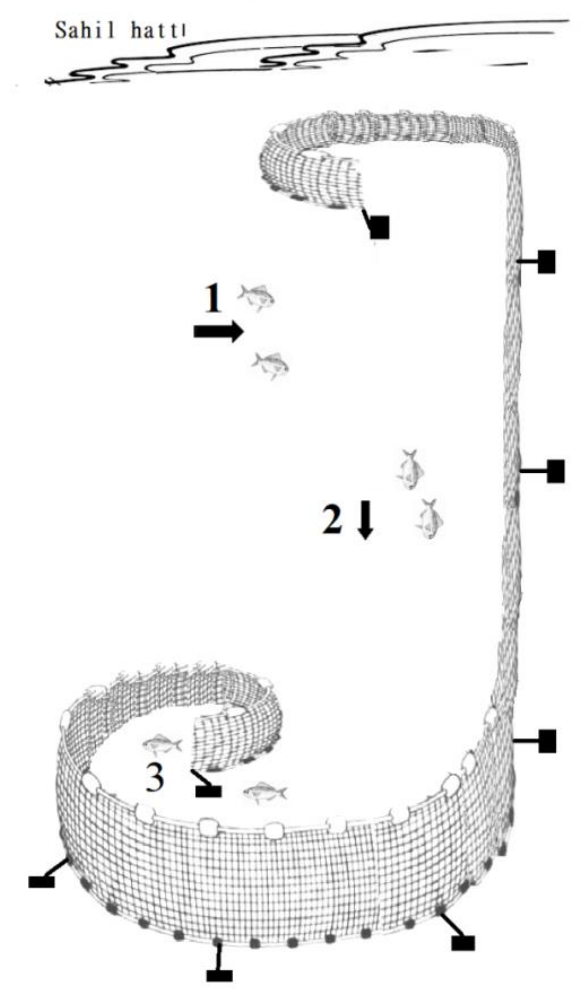

Şekil 2. Dönek yöntemi ile avcılık operasyonu

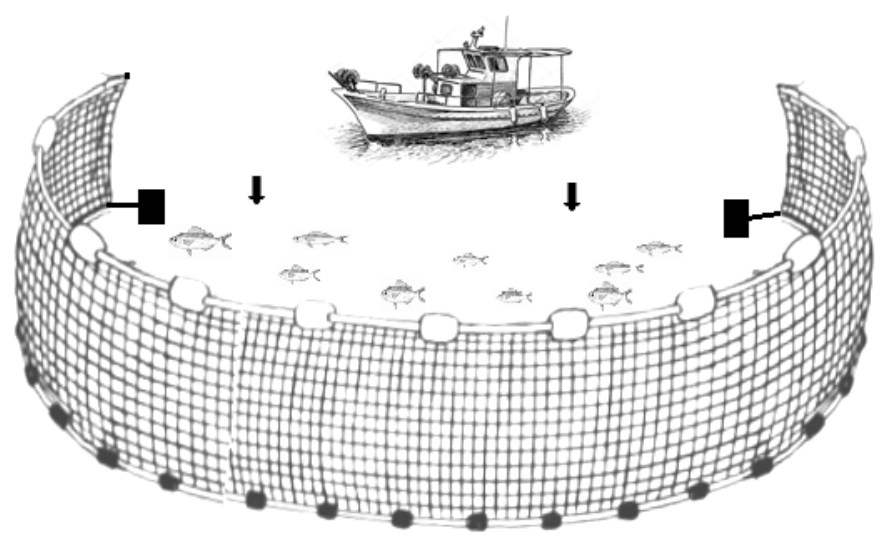

Şekil 3. Voli yöntemi ile avcılık operasyonu 
Her av operasyonundan sonra farklı göz genişliğine sahip ağların yakaladı̆̆ı balıklar ayrı yerlere alınmıştır. Yakalanan balıkların toplam boy ölçümleri $1 \mathrm{~mm}$ hassasiyetinde ölçüm tahtası ile yapılmış, toplam ağırlıkları ise 1 gr hassasiyetinde terazi ile tartılarak kayıtları alınmıştır.

Deneme ağlarının seçiciliğinin belirlenmesinde SELECT (Share Each Lengthclass Catch Total) metot kullanılmıştır (Millar, 1992; Millar ve Fryer, 1999; Millar ve Holst, 1997). Bu metotta j boyutundaki ağ gözüne yakalanan 1 uzunluğundaki balıkların sayısı $\mathrm{n}_{\mathrm{lj}}$ bir Poisson dağılımına sahip olduğu farz edilir ve aşağıda belirtildiği gibi ifade edilir;

$$
\mathrm{n}_{\mathrm{lj}} \approx \mathrm{n}_{\mathrm{lj}} \approx \text { Pois }\left(\mathrm{p}_{\mathrm{j}} \lambda_{\mathrm{l}} \mathrm{r}_{\mathrm{j}}(1)\right)
$$

Burada; $\lambda l$ ağ ile karşılaşan 1 boyundaki balıkların bolluğu; pj (1): göreceli balıkçılık yoğunluğunu ( $\mathrm{j}$ ağ gözünün avlayabileceği 1 boyundaki balıkların göreceli bolluğu) ifade etmektedir. J ağ gözüne sahip av aracina temas eden 1 boyundaki balık sayısının

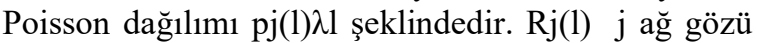
için seçicilik eğrisini meydana getirmektedir.

Nlj'nin log-likelihood dağılımı aşağıda görülmektedir;

$$
\sum_{l} \sum_{j}\left\{n_{l} \log \left[p_{j} \lambda_{l} r_{j}(l)\right]-p_{j} \lambda_{l} r_{j}(l)\right\}
$$

Denemeler sonucunda elde edilen veriler PASGEAR II version 2.6 (Kolding ve Skålevik, 2011) bilgisayar programı kullanılarak değerlendirmeler yapılmıştır. Program SELECT metot ile beş farklı modele (Normal location, normal scale, log-normal, gamma ve bi-modal) ait parametreleri hesaplamaktadır. $\mathrm{Bu}$ parametreler içinde en düşük model sapma değerini veren model en iyi model olarak seçilmektedir. Seçicilik eğrileri bu modelin parametrelerine göre excel programı kullanılarak çizdirilmiştir. SELECT metoda ait model denklemleri aşağıda verilmiştir.

Normal Location :

$$
\exp \left(-\frac{\left(L-k \cdot m_{j}\right)^{2}}{2 \sigma^{2}}\right)
$$

Normal Scale ;

$$
\exp \left(-\frac{\left(L-k_{1} \cdot m_{j}\right)^{2}}{2 k_{2}^{2} \cdot m_{j}^{2}}\right)
$$

Log-Normal ;

$$
\frac{1}{L} \exp \left(\mu+\log \left(\frac{m_{j}}{m_{1}}\right)-\frac{\sigma^{2}}{2}-\frac{\left(\log (L)-\mu-\log \left(\frac{m_{j}}{m_{1}}\right)\right)^{2}}{2 \sigma^{2}}\right)
$$

Gamma ;

$$
\left(\frac{L}{(\alpha-1) \cdot k \cdot m_{j}}\right)^{\alpha-1} \exp \left(\alpha-1-\frac{L}{k \cdot m_{j}}\right)
$$

Bi-modal ;

$$
\exp \left(-\frac{\left(L-k_{1} \cdot m_{j}\right)^{2}}{2 k_{2}^{2} \cdot m_{j}^{2}}\right)+c \cdot \exp \left(-\frac{\left(L-k_{3} \cdot m_{j}\right)^{2}}{2 k_{4}^{2} \cdot m_{j}^{2}}\right)
$$

PASGEAR II programında yapılan analizler sonucunda SELECT metotta belirlenen en iyi modelin parametreleri kullanılarak Microsoft excel programında her bir yöntemde farklı göz genişliklerindeki ağların optimum yakalama boyları ve seçicilik aralıkları belirlenmiştir. Bu aralıklar aynı gözlerde farklı avcılık yöntemleri için karşılaştırılmıştır. $\mathrm{Bu}$ karşılaştırmalar sonucunda avcılık yönteminin seçicilik farkının olup olmadığı ortaya konulmuştur. Farklı yöntemler ile aynı göz genişliğine yakalanan balıkların boy dağılımları arasında istatistiksel fark olup olmadığ Kolmogorov Smirnov testi yapılarak analiz edilmiştir.

\section{Bulgular}

Çalışma periyodunda dönek yönteminde 446, voli yönteminde 530 olmak üzere toplamda 976 adet Kupes balığ1 yakalanmıştır. Minimum boy $12,7 \mathrm{~cm}$, maksimum boy $27,8 \mathrm{~cm}$ 'dir. Minimum ağırlık $35 \mathrm{gr}$, maksimum ağırlık 212 gr'dır (Tablo 1).

Yakalanan balıkların ağlara göre boy - frekans dağılımları Şekil 4'te verilmiştir. Voli yöntemi ile yakalanan balıkların boy ortalamalarının dönek yönteminde yakalananlara göre daha büyük oldukları görülmektedir.

Seçicilik parametreleri, dönek yöntemi için en düşük model sapma değerini veren Normal Location ve voli yöntemi için Normal Scale modeliyle hesaplanmıştır (Tablo 2). Bu modellere göre, 20, 22, 23 ve $25 \mathrm{~mm}$ göz genişliğine sahip galsama ağlarında optimum yakalama boyları dönek yönteminde sirasiyla 16,25 cm, $17,87 \mathrm{~cm}, 18,68 \mathrm{~cm}, 20,31 \mathrm{~cm}$, voli yönteminde ise 19,13 cm, 21,04 cm, $22 \mathrm{~cm}, 23,91 \mathrm{~cm}$ olarak hesaplanmıştır (Tablo 3). Seçicilik analizleri sonucunda, voli yöntemi ile yapılan avcılıkta, dönek yöntemine göre ortalama $3-3,5 \mathrm{~cm}$ daha büyük balıkların yakalanabileceği hesaplanmıștır. 
Tablo 1. Denemelerde ağlara yakalanan balıkların maksimum, minimum ve ortalama boy ve ağırlıkları

\begin{tabular}{|c|c|c|c|c|c|c|c|c|}
\hline $\begin{array}{c}\text { Ă ğ Göz } \\
\text { Genişliği }\end{array}$ & $\mathbf{N}$ & $\begin{array}{c}\text { Minimum } \\
\text { Boy }(\mathrm{cm})\end{array}$ & $\begin{array}{c}\text { Maksimum } \\
\text { Boy }(\mathbf{c m})\end{array}$ & $\begin{array}{c}\text { Ortalama } \\
\text { Boy }(\mathrm{cm}) \\
\pm \text { Std. Hata }\end{array}$ & $\begin{array}{l}\text { Minimum } \\
\text { A ğırlık (g) }\end{array}$ & $\begin{array}{c}\text { Maksimum } \\
\text { Ağırlık (g) }\end{array}$ & $\begin{array}{c}\text { Ortalama } \\
\text { Ağırlık (g) } \\
\pm \text { Std. Hata }\end{array}$ & $\begin{array}{l}\text { Avcılık } \\
\text { Yöntemi }\end{array}$ \\
\hline $20 \mathrm{~mm}$ & 104 & 15,8 & 20,4 & $17,58 \pm 0,1$ & 36 & 94 & $59,43 \pm 1,0$ & \multirow{4}{*}{ Dönek } \\
\hline $22 \mathrm{~mm}$ & 94 & 16,4 & 20,6 & $18,15 \pm 0,1$ & 48 & 94 & $64,23 \pm 0,8$ & \\
\hline $23 \mathrm{~mm}$ & 105 & 12,7 & 20,8 & $17,92 \pm 0,1$ & 35 & 97 & $63,04 \pm 0,9$ & \\
\hline $25 \mathrm{~mm}$ & 143 & 16,8 & 21,2 & $18,52 \pm 0,1$ & 48 & 99 & $68,09 \pm 0,8$ & \\
\hline $20 \mathrm{~mm}$ & 118 & 16,3 & 21,9 & $19,05 \pm 0,1$ & 49 & 116 & $74,74 \pm 1,5$ & \multirow{4}{*}{ Voli } \\
\hline $22 \mathrm{~mm}$ & 127 & 17 & 24,6 & $20,47 \pm 0,1$ & 53 & 174 & $93,40 \pm 1,8$ & \\
\hline $23 \mathrm{~mm}$ & 135 & 18,1 & 26,3 & $21,33 \pm 0,2$ & 59 & 186 & $106,94 \pm 2,7$ & \\
\hline $25 \mathrm{~mm}$ & 150 & 18,1 & 27,8 & $21,56 \pm 0,2$ & 61 & 212 & $108,00 \pm 2,5$ & \\
\hline
\end{tabular}

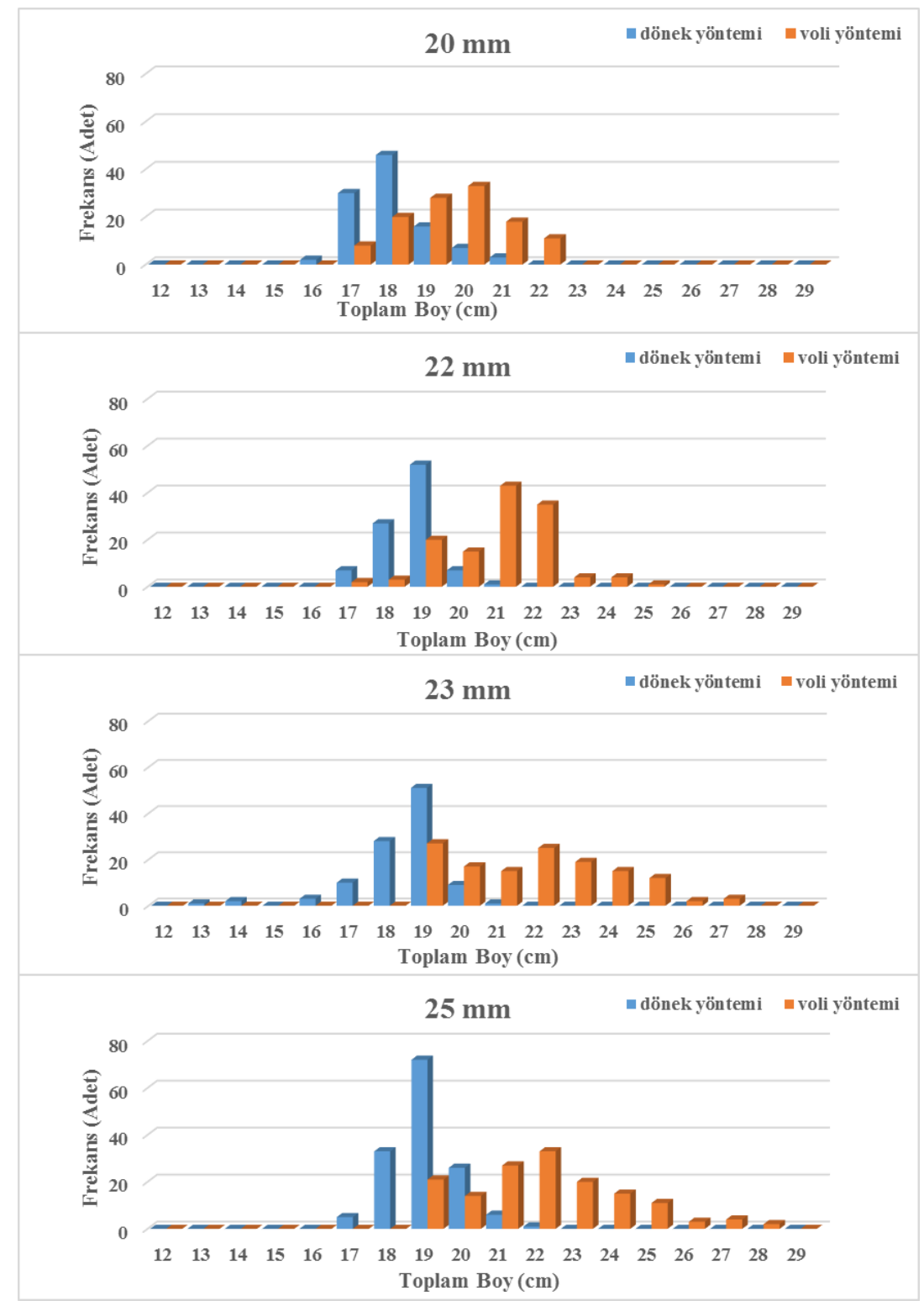

Şekil 4. Dönek ve voli yöntemi ile ağlara yakalanan balıkların boy dağılımları 
Tablo 2. SELECT metot kullanılarak yapılan analizler sonucunda her iki yöntem için hesaplanan model parametreleri

\begin{tabular}{|c|c|c|c|c|c|}
\hline Model & Parametre & $\begin{array}{l}\text { Sapma } \\
\text { Değeri }\end{array}$ & p-value & $\begin{array}{c}\text { Serbestlik } \\
\text { Derecesi (d.f.) }\end{array}$ & $\begin{array}{l}\text { Avcılık } \\
\text { Yöntemi }\end{array}$ \\
\hline Normal location & $(\mathrm{k} ; \sigma)=(8,126 ; 2,687)$ & 73,866 & 0,0000001 & 23 & \\
\hline Normal scale & $(\mathrm{k} 1 ; \mathrm{k} 2)=(8,258 ; 1,265)$ & 76,181 & 0,0000001 & 23 & \\
\hline Lognormal & $(\mu 1 ; \sigma)=(2,818 ; 0,149)$ & 76,383 & 0,0000001 & 23 & Dönek \\
\hline Gamma & $(k ; \alpha)=(0,185 ; 45,455)$ & 76,158 & 0,0000001 & 23 & \\
\hline Bi-modal & $\begin{array}{c}(\mathrm{k} 1 ; \mathrm{k} 2 ; \mathrm{k} 3 ; \mathrm{k} 4 \\
\mathrm{w})=\text { Hesaplanamad }\end{array}$ & Hesaplanamad 1 & Hesaplanamadi & Hesaplanamadi & \\
\hline Normal location & $(\mathrm{k} ; \sigma)=(9,411 ; 2,526)$ & 81,695 & 0,000003 & 32 & \\
\hline Normal scale & $(\mathrm{k} 1 ; \mathrm{k} 2)=(9,566 ; 1,108)$ & 75,30 & 0,000024 & 32 & \\
\hline Lognormal & $(\mu 1 ; \sigma)=(2,952 ; 0,116)$ & 79,831 & 0,000006 & 32 & Voli \\
\hline Gamma & $(k ; \alpha)=(0,128 ; 75,278)$ & 78,167 & 0,00001 & 32 & \\
\hline Bi-modal & $\begin{array}{c}(\mathrm{k} 1 ; \mathrm{k} 2 ; \mathrm{k} 3 ; \mathrm{k} 4 \\
\mathrm{w})=\text { Hesaplanamad }_{1}\end{array}$ & Hesaplanamadi & Hesaplanamadi & Hesaplanamadi & \\
\hline
\end{tabular}

Tablo 3. Avcılık yöntemlerine göre deneme ağlarının hesaplanan optimum boy ve yayılım değerleri

\begin{tabular}{ccccc}
\hline $\begin{array}{c}\text { Ağ Göz } \\
\text { Genişliği }\end{array}$ & $\begin{array}{c}\text { Optimum } \\
\text { Boy (cm) }\end{array}$ & $\begin{array}{c}\text { Yayılım } \\
(\mathbf{c m})\end{array}$ & $\begin{array}{c}\text { Avcilık } \\
\text { Yöntemi }\end{array}$ & $\begin{array}{c}\text { Seçicilik } \\
\text { Modeli }\end{array}$ \\
\hline $\mathbf{2 0} \mathbf{~ m m}$ & 16,25 & 2,687 & & \\
$\mathbf{2 2} \mathbf{~ m m}$ & 17,87 & 2,687 & Dönek & $\begin{array}{c}\text { Normal } \\
\text { Location }\end{array}$ \\
$\mathbf{2 3} \mathbf{~ m m}$ & 18,68 & 2,687 & & \\
$\mathbf{2 5} \mathbf{~ m m}$ & 20,31 & 2,687 & & \\
\hline $\mathbf{2 0} \mathbf{~ m m}$ & 19,13 & 2,216 & & \\
$\mathbf{2 2} \mathbf{~ m m}$ & 21,04 & 2,438 & Voli & $\begin{array}{c}\text { Normal } \\
\text { Scale }\end{array}$ \\
$\mathbf{2 3} \mathbf{~ m m}$ & 22,00 & 2,548 & & \\
$\mathbf{2 5} \mathbf{~ m m}$ & 23,91 & 2,770 & & \\
\hline
\end{tabular}

Seçicilik analizleri sonucunda, farklı yöntemler için çizdirilen seçicilik eğrileri Şekil 5'te gösterilmektedir. Voli yöntemi ile yakalanan balıkların optimum yakalama boyları dönek yöntemine göre daha büyük olduğu görülmektedir.
Kolmogorov - Smirnov testi sonuçları, voli ve dönek yöntemi ile yakalanan aynı göz genişliğine sahip ağların yakaladığı balıkların boy dağılımları arasında istatistiksel farkın önemli olduğunu göstermiştir $(\mathrm{P}<0,05)$. 


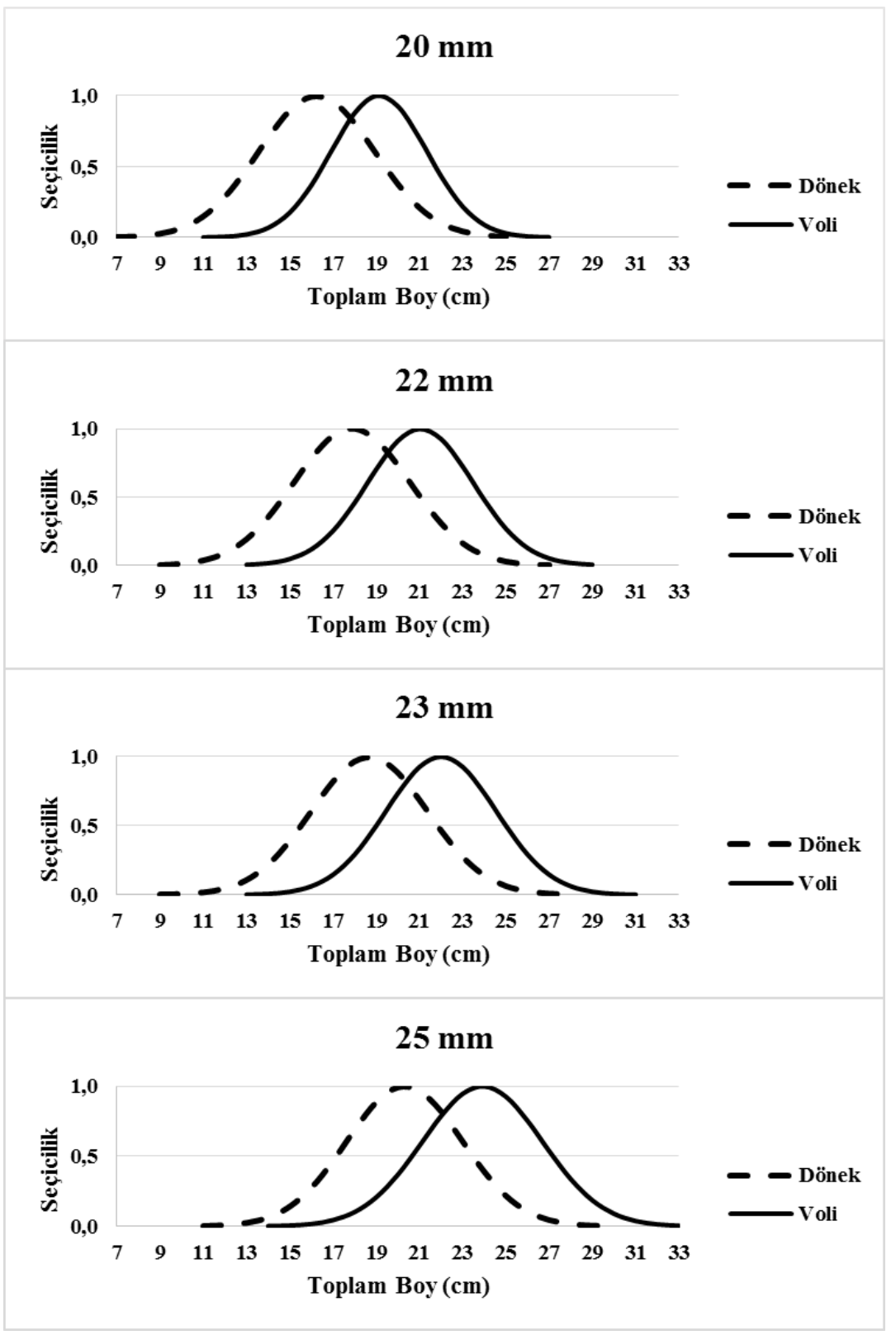

Şekil 5. Deneme ağları için her iki yöntemde çizdirilen seçicilik eğrilerinin karşılaştırılması

\section{Tartışma ve Sonuç}

$\mathrm{Bu}$ çalışmada iki farklı avcılık yönteminin galsama ağları seçiciliği üzerindeki etkisi incelenmiştir. Çalışma sonucunda voli yöntemi ile yakalanan balıkların optimum yakalama boyu dönek yöntemi ile avlananlardan 3-3,5 $\mathrm{cm}$ daha büyük olduğu belirlenmiştir. Yapılan Kolmogorov - Smirnov test sonuçları da bunu doğrulamıştır $(P<0,05)$. Voli yönteminin uygulanmasında balıklar ağa doğru korkutularak sürülür. Bundan dolayı ağa çarpma hızları, dönek yöntemine göre çok daha fazladır. Dönek yönteminde balıklar günlük göç hareketleri ile ağlara yakalanmaktadır. Nitekim Kumova ve diğ. (2015) donam faktörünü test ettikleri çalı̧̧mada, bu faktörün ancak seçicilikte avcılık yöntemi gibi diğer faktörlerle birlikte etkili olabileceğini belirtmiştir. Her ne kadar Hamley (1975) avcılık yönteminin seçiciliğe etkisi olduğunu belirtmiş olsa da, literatürde bu konuyu ele alan bir seçicilik çalışmasına rastlanılamamıştır.

Hickford ve Schiel (1996), büyük balıkların genellikle operkulum hizasındaki vücut çevresi önünden, küçük balıkların ise galsamasından ya da ağa saplanarak gerçekleștiğini ifade etmişlerdir. Yapılan denemeler sonucu yakalan balıkların küçük olması nedeniyle neredeyse tamamı galsamasından ya da ağa saplanarak yakalanmışlardır. Dolayısı ile bu vücut yapısına sahip ve kullanılan ağ göz genişliğine göre normal şartlarda galsamasindan ya da ağa saplanarak yakalanabilecek büyüklükteki balıklar voli yönteminde korkutulması nedeniyle yüksek yüzme 
hızı ile ağa geldikleri için ağ gözünün içinden geçebilmektedir.

Kupes balığı için yapılan seçicilik çalışmaları incelendiğinde; Ayaz ve diğ. (2010) ip kalınlıklarını konu aldıkları çalışmalarında benzer ağları voli yöntemi kullanarak karşılaştırmıştır. Denemeler sonucunda optimum yakalama boylarını $22 \mathrm{~mm}, 23$ $\mathrm{mm}$ ve $25 \mathrm{~mm}$ göz genişliğine sahip ağlar için sırası ile $23,3 \mathrm{~cm}, 24,4 \mathrm{~cm}$ ve $26,5 \mathrm{~cm}$ olarak belirlemiştir. Kumova ve diğ . (2015) donam faktörünü inceledikleri çalışmalarında 2 ağın bizim çalışmamızla benzerlik gösterdiği görülmektedir. Denemelerinde $22 \mathrm{~mm}$ ve $25 \mathrm{~mm}$ göz genişliğine sahip ağlar için optimum yakalama boylarını $21,9 \mathrm{~cm}$ ve 24,9 olarak hesaplamışlardır. Çalışmamızda voli yöntemi ile kullanılan ağlarda optimum yakalama boyları sırası ile $22 \mathrm{~mm}, 23 \mathrm{~mm}$ ve $25 \mathrm{~mm}$ göz genişliğine sahip ağlar için sırası ile $21 \mathrm{~cm}, 22 \mathrm{~cm}$ ve $23,9 \mathrm{~cm}$ olarak belirlenmiştir. $\mathrm{Bu}$ durumun çalışmaların yapıldığ 1 mevsimsel farklardan kaynaklandığını düşünmekteyiz.

Kupes balığının ilk üreme boyu üzerine yapılan çalışmalarda erkek ve dişi bireylerin ilk üreme boylarının sırasıyla 9,35 cm ve 12,96 cm olduğu tespit edilmiştir (Kınacıgil, İlkyaz, Metin, Ulaş, Soykan, Akyol ve Gurbet, 2008). Güney Portekiz'de gerçekleştirilen bir başka çalışmada ise $15,22 \mathrm{~cm}$ olarak belirlenmiştir (Monteiro, Bentes, Coelho, Correia, Goncalves, Lino, Ribeiro, ve Erzini, 2006). Gıda, Tarım ve Hayvancılık Bakanlığ 1 tarafından 2020 Ağustos ayında yayınlanan $5 / 1$ sayılı ticari avcilığ 1 düzenleyen tebliğde Kupes balığ1 avcılığ için herhangi bir dönem ve boy kısitlaması bulunmamaktadır. Gerçekleştirilen çalışmada kullanılan 20,22, 23, $25 \mathrm{~mm}$ göz genişliğine sahip galsama ağlarının optimum yakalama boylarının literatürdeki değerlerden yüksek olması nedeniyle Kupes stoğunun devamlılığı açısından deneme ağlarının tehdit oluşturmadığ 1 tespit edilmiştir. Ancak ticari olarak düşünüldüğünde balıkçılar ile yapılan görüşmeler sonucunda $17 \mathrm{~cm}$ ve daha az uzunluktaki Kupes balıklarının ticari değerinin çok az olması nedeniyle ile Kupes balığı avcılığ 1 için $22 \mathrm{~mm}$ ve daha büyük göz genişliğine sahip ağların kullanılmasının önemli olduğu ortaya çıkmaktadır.

Çalışma sonuçları seçiciliğin avcılık yönteminden önemli derecede etkilendiğini göstermiştir. Özellikle kupes gibi fusiform vücut yapısına sahip olan balıklarda bu durumun önemli olduğunu düşünmekteyiz. A $\breve{g}$ gözlerinin seçiciliğini etkileyen pek çok faktör olduğu için yapılan tüm çalışmaların bir bütün olarak değerlendirilmesi ve öyle karar alınmasının sürdürülebilir balıkçılık açısından son derece önemli olduğu çalışmamız sonucunda bir kez daha ortaya çıkmıştır.

\section{Kaynaklar}

Altinağac, U., Ayaz, A., Özekinci, U., \& Öztekin A. (2008). Edremit Körfezi Dip Uzatma Ağlarının Teknik Özellikleri ve Yapısal Farklılıkları. Journal of Fishery Sciences, 2(3): 432-439.

Ayaz, A., Altınağaç, U., Öztekin A., \& Özekinci, U. (2009). The Effect of Seasons on Gill Net Selectivity. Aquatic Sciences And Engineering, 34(4):116-121.

Doi:https://doi.org/10.26650/ASE2019575395.

Ayaz, A., Altınağaç, U., Özekinci, U., Cengiz, Ö., \& Öztekin A. (2010). Effects of hanging ratio on gillnet selectivity for annular sea bream (Diplodus annularis) in the northern Aegean Sea, Turkey. Journal of Animal and Veterinary Advances, 9(7):1137-1142.

Clarke, J.R. (1960). Report on selectivity of fishing gear. ICNAF Spec. Publ., 2: 27-36.

Gabriel, O., Lange, K., Dahm, E. \& Wendt, T. (Eds.) (2005). Von Brandt's Fish catching methods of the World, Blackwell, Oxford, UK, 536 pp.

Gulland J.A., (1969). Manual of Methods For Fish Stock Assessment, Part I, Fish Population Analysis, Man FAO. Fish Sci., 4: 154.

Hamley, J.M. (1975). Review of gillnet selectivity. Journal of the Fisheries Research Board of Canada,32:1943-1969.

Doi:https://doi.org/10.1139/f75-233.

Hickford, M.J.H. \& Schiel, D.R. (1996). Gillnetting in southern New Zealand, Duration effects of sets and entanglement modes of fish. Fishery Bulletin, 94 (4): 669-677.

Kınacıgil, H.T., İlkyaz, A.T., Metin, G., Ulaş, A., Soykan, O., Akyol, O., \& Gurbet, R. (2008). Balıkçılık Yönetimi Açısından Ege Denizi Demersal Stoklarının İlk Ürüme Boyları, Yaşları Parametrelerinin Tespiti. TÜBITAK-ÇAYDAG Proje No: 103Y132, 327p.

Kolding, J. \& Skålevik, Å. (2011). PasGear 2. A database package for experimental or artisanal fisherydata.Version 2.5. available at http://www.imr.no/forskning/bistandsarbeid/nansi s/pasgear2/en.

Kumova, C. A., Altinağac, U., Öztekin, A., Ayaz, A., \& Aslan, A. (2015). Effect of Hanging Ratio on Selectivity of Gillnets for Bogue Boops boops L 1758. Turkish Journal of Fisheries and Aquatic Sciences, 15(2): 567-573. Doi: 10.4194/13032712-v15_2_43.

Millar, R.B. (1992). Estimating the Size-Selectivity of Fishing Gear by Conditioning on the Total Catch. Journal of the American Statistical Association, 87, 962-968. 
Millar, R.B., \& Fryer, R.J. (1999). Estimating the sizeselection curves of towed gears, traps, nets and hooks. Reviews in Fish Biology and Fisheries, 9,89-116.

Doi:https://doi.org/10.1023/A:1008838220001.

Millar, R.B., \& Holst, R. (1997). Estimation of gillnet and hook selectivity using log-linear models, Ices Journal of Marine Science, 54, 471-477. Doi: https://doi.org/10.1006/jmsc.1996.0196.

Monteiro, P., Bentes, L., Coelho, R., Correia, C., Goncalves, J.M.S., Lino, P.G., Ribeiro, J., \& Erzini, K. (2006). Age and growth, mortality, reproduction and relative yield per recruit of the bogue, Boops boops Linne, 1758 (Sparidae), from the Algarve (south of Portugal) longline fishery. Journal of Applied Ichthyology, 22, 345-352. Doi: https://doi.org/10.1111/j.14390426.2006.00756.x.

Von Brandt, A. (1975). Enmeshing nets: gillnets and entangling nets - the theory of their efficiency, Proc. EIFAC Symp. 